\title{
Dielectric Property of Solution Analyzed by using pn-junction Array
}

\author{
Shunsuke Ohata and Akira Kawai* \\ Department of Electrical Engineering, Nagaoka University of Technology, \\ 1603-1 Kamitomioka, Nagaoka, Niigata 940-2188, Japan \\ (*Correspondingauthor,kawai@nagaokaut.ac.jp)
}

\begin{abstract}
Drying property of water thin film formed on a pn-junction array substrate is characterized based on dielectric analysis. In wetting processes such as pattern development, wet etching wet cleaning and drying are recognized as important processes in order to fabricate high quality electronic devices. The pn-junction array is designed with a combination of micro pattern networks. By using a FRA (Frequency Response Analyzer) system, the drying process of water thin film can be monitored. A rapid decrease of capacitance value is observed as vanishing the micro meniscus bridge. The application of endpoint detector of drying of water thin layer is discussed.
\end{abstract}

Keywords: pn-junction, dielectric property, FRA, water thin film, micro meniscus, Laplace force

\section{Introduction}

Recently, wetting processes such as pattern development, wet etching and wet cleaning, drying technology are recognized as important technologies in order to fabricate high quality electronic devices. In this regard, the concern with the microfluidic systems, micro-TAS (Total Analysis System) and wet MEMS (micro electronic mechanical systems) have been growing for industry area such as human health, agriculture and analytical chemical field.[1-4] In these devices combined with a micro channel, the detection of fluid position is one of most important technology. In this paper, a pn-junction array is designed with a combination of micro channel networks. By using a FRA (Frequency Response Analyzer), the drying process of water thin film is characterized as shown in Fig.1. Particularly, we focus on the drying point detection of micro water meniscus by the dielectric measurement.

\section{Experiment}

2.1 Preparation of pn-junction array

The fabrication processes of the pn-junction array is summarized in Table 1. As a substrate for

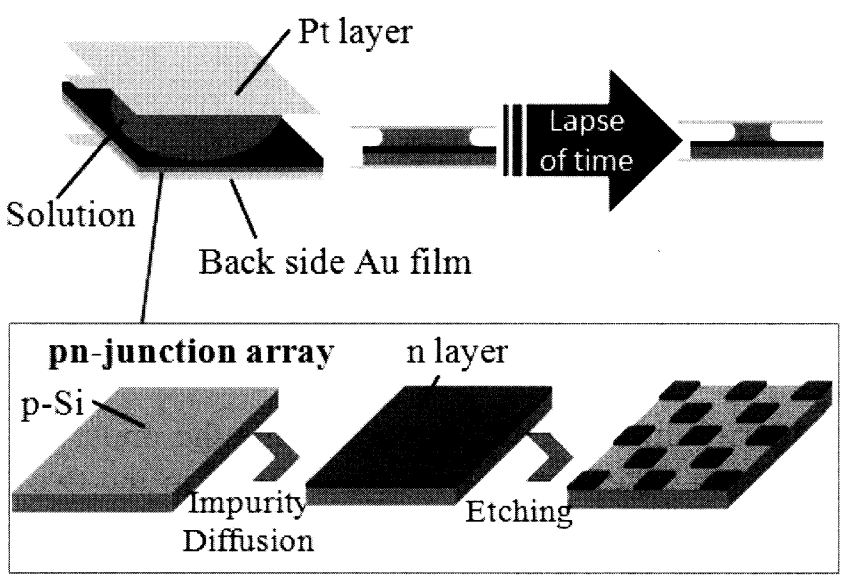

Fig.1 Schematic diagram of experimental setup for the detection of water thin layer drying behavior.

the pn-junction array, a p-type $\mathrm{Si}(100)$ substrate was used. For the impurity diffusion, a P-SOG solution (OCDT-1, P-59250 by Tokyo Ohka Kogyo Co., Ltd.) was used. The micro channel patterns were fabricated by the photolithography technology. The pn-junction array of $0.5 \mathrm{~mm}^{2}$ in lattice structure was formed on $\mathrm{Si}(100)$ substrate by using optical mask as shown in Fig.2. Figure 3 shows a temperature profile during the phosphor

$\begin{array}{lll}\text { Received } & \text { May } & 14,2010 \\ \text { Accepted } & \text { June } & 11,2010\end{array}$


Table.1 Fabrication condition of the pn-junction array sample

(a) pn-junction fabrication

\begin{tabular}{|c|c|c|}
\hline No. & Process & Parameter \\
\hline 1 & SOG coating & $\begin{array}{l}\text { OCD T-1 P-59250, } \\
\text { supported by Tokyo Ohka } \\
\text { Kogyo Co., Ltd. }\end{array}$ \\
\hline 2 & Pre Bake & $120^{\circ} \mathrm{C}$ for $60 \mathrm{~min}$ \\
\hline 3 & $\begin{array}{l}\text { Impurity } \\
\text { diffusion }\end{array}$ & $\begin{array}{l}\mathrm{N}_{2} \text { gas }(99.999 \%) \text { purge } \\
\text { Temperature profile: see } \\
\text { Fig. } 3\end{array}$ \\
\hline 4 & $\mathrm{HF}$ treatment & $5 \mathrm{wt} \%$ aq. for $2 \mathrm{~min}$ \\
\hline
\end{tabular}

(b) micro channel pattern fabrication

\begin{tabular}{lll}
\hline No. & Process & Parameter \\
\hline 1 & $\begin{array}{l}\text { HMDS } \\
\text { treatment }\end{array}$ & HMDS vapor for 20min \\
\hline 2 & Spin Coating & $\begin{array}{l}\text { Resist: i-line positive } \\
500 \mathrm{rpm} / 5 \mathrm{~s}, 3000 \mathrm{rpm} / 30 \mathrm{~s}\end{array}$ \\
\hline 3 & Pre bake & $90^{\circ} \mathrm{C}$ for $90 \mathrm{~s}$ \\
\hline 4 & Exposure & $\mathrm{UV}(\lambda=365 \mathrm{~nm})$ for $0.5 \mathrm{~s}$ \\
\hline 5 & Development & $\mathrm{TMAH} 2.38 \mathrm{aq}$. for $1 \mathrm{~min}$ \\
\hline 6 & Rinse & DI water for $30 \mathrm{~s}$ \\
\hline 7 & Post bake & $180^{\circ} \mathrm{C}$ for $10 \mathrm{~min}$ \\
\hline 8 & RIE (Reactive & Etching Gas: $\mathrm{CF}_{4}$ \\
& Ion Etching) & $50 \mathrm{~W}$ for $12 \mathrm{~min}$ \\
\hline 9 & Ashing & $\begin{array}{l}\text { Process gas: } \mathrm{O}_{2} \\
200 \mathrm{~W} \text { for } 5 \mathrm{~min}\end{array}$ \\
\hline 10 & $\begin{array}{l}\text { Back side } \mathrm{Au} \\
\text { sputtering }\end{array}$ & $\begin{array}{l}\text { Purge gas: } \mathrm{Ar}(99.9999 \%) \\
1 \mathrm{kV}, 8 \mathrm{~mA} \text { for } 5 \mathrm{~min}\end{array}$ \\
\hline 11 & Wire bonding & \\
\hline 12 & descum & $\mathrm{O}_{2}$ plasma ashing \\
& process & $200 \mathrm{~W}$ for $30 \mathrm{~s}$ \\
\hline
\end{tabular}

impurity diffusion in a furnace. while the impurity diffusion. The impurities were diffused in the two step heating conditions, $500^{\circ} \mathrm{C}$ for $30 \mathrm{~min}$ and $930^{\circ} \mathrm{C}$ for $1 \mathrm{~h}$. Figure 4 shows the photographs of the pn- junction array samples. The contrast of resist patterns is clear. After the reactive ion etching of $\mathrm{Si}$ substrate with $\mathrm{CF}_{4}$ gas, the micro square patterns about $0.5 \mu \mathrm{m}$ depth were fabricated.

Dielectric properties of water thin layer remaining on the substrate were measured by using a gap structure as illustrated in Fig.1. A Pt sputtered glass plate was used as an opposite electrode. The gap width was $1 \mathrm{~mm}$. The capacitance of the sample was measured at the frequencies of $1 \mathrm{~Hz}, 100 \mathrm{~Hz}$ and $10 \mathrm{kHz}$. The reference resistance $V_{R}$ of $10 \mathrm{k} \Omega$ was chosen for the FRA measurement as shown in Fig.5.

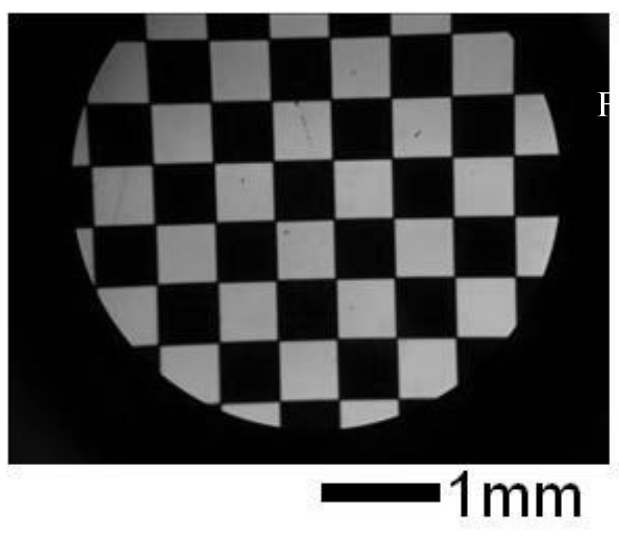

Fig.2 Photograph of dry plate photo mask.

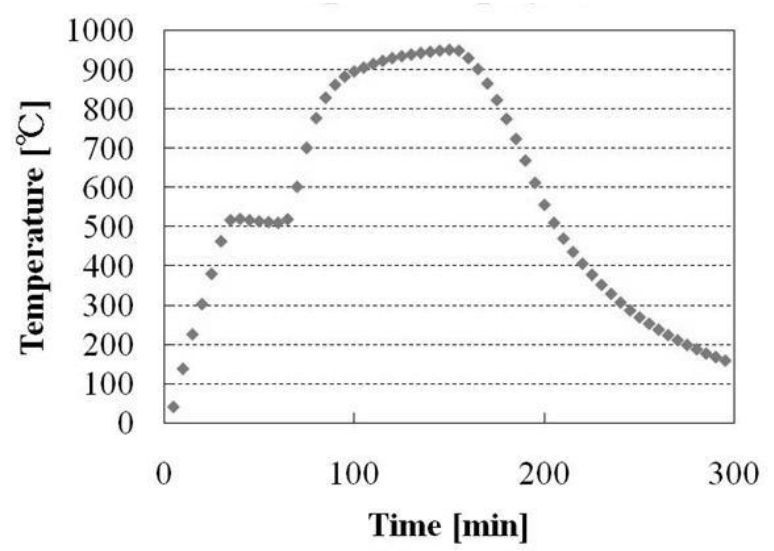

Fig.3 Temperature profile in impurity diffusion.

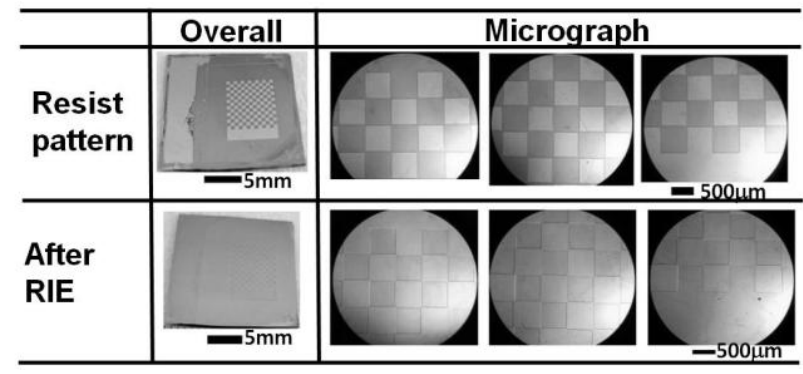

Fig.4 Photographs of pn-junction array in square lattice pattern formed on Si substrate.

2.2 Dielectric property measurement by using FRA

The capacitance of the sample was measured in both dry and wet conditions. DI (deionized) water was injected into the gap by using a syringe. In general, FRA has an advantage for precise measurement of dielectric properties in lower frequency. By employing a measurement circuit in Fig.5, an impedance of a sample can be determined precisely, and a gain and phase difference between the signals of $\mathrm{CH} 1$ and $\mathrm{CH} 2$ can be obtained in the FRA analysis. In Fig.6, a vector diagram of the measurement circuit containing a water meniscus is shown. 


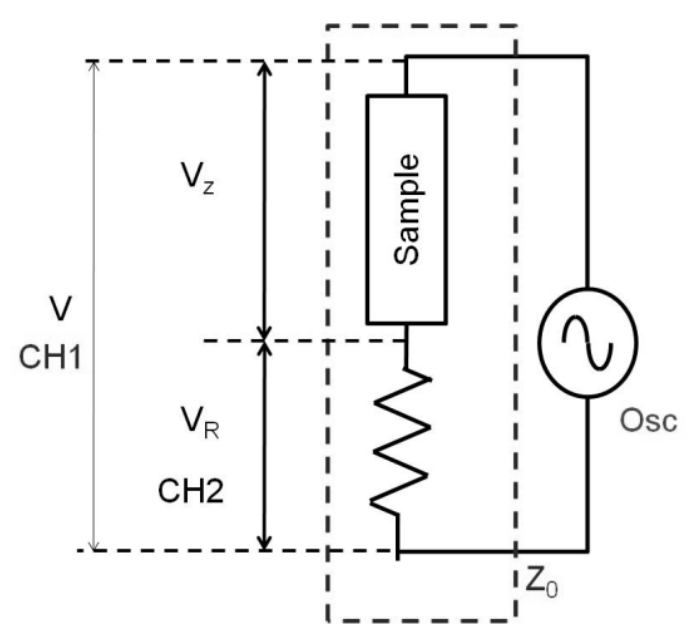

Fig.5 Equivalent electric circuit of FRA measurement system for water meniscus sample.

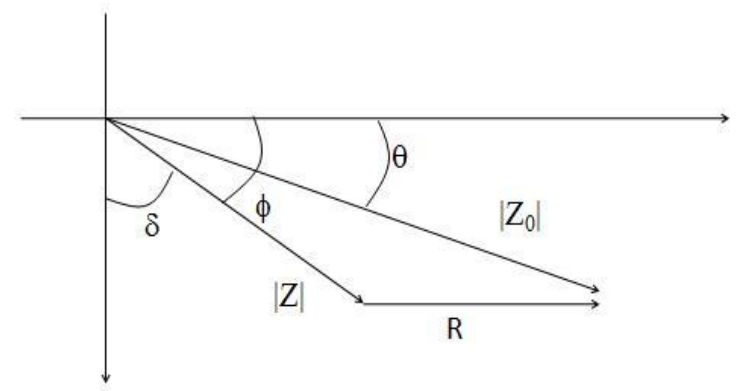

Fig.6 Vector diagram of FRA circuit.

The phase difference $\phi$ between $|Z|$ and $\mathrm{R}$, and the phase difference $\delta$ are defined in Fig. 6. These values are expressed as follows.

$$
\begin{aligned}
& \tan \phi=\frac{\left|Z_{0}\right| \sin \theta}{\left|Z_{0}\right| \cos \theta-R}, \\
& \delta=|-90+\phi| .
\end{aligned}
$$

The phase difference $\phi$ is given by

$$
\phi=\tan ^{-1}\left(\frac{\sqrt{Z^{2}+R^{2}} \sin \theta}{\sqrt{Z^{2}+R^{2}} \cos \theta-R}\right) .
$$

The dielectric loss tangent, $\tan \delta$, is obtained from Eqs. 2 and 3. The capacitance of the sample $C[\mathrm{~F}]$ is given by

$$
C=\frac{B}{\omega}=\frac{Y \sin \phi}{\omega}=\frac{\sin \phi}{Z \omega} .
$$

\section{Results and Discussion}

The drying behavior of water thin layer is observed by using an optical microscope. Figure 7 shows the photographs for water layer drying.

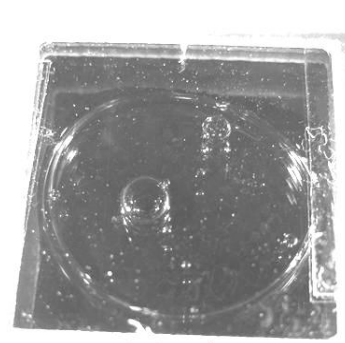

(a) $0 \mathrm{~h}$

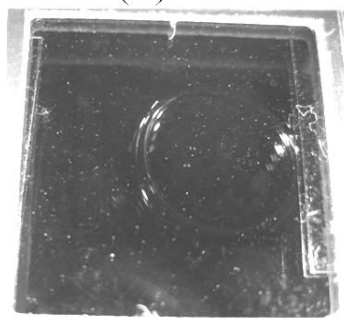

(c) $15 \mathrm{~h}$

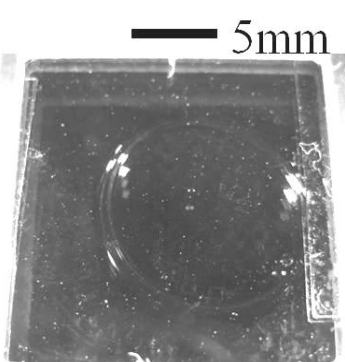

(b) $9 \mathrm{~h}$

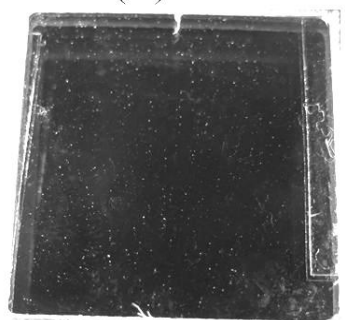

(d) $28 \mathrm{~h}$
Fig.7 Photographs of meniscus bridge formed in a gap at a lapse of $0,540,900,1680 \mathrm{~min}$, respectively.

At the initial stage of drying, it is clearly observed that the water meniscus formed between the pn-junction array and the opposite electrode. At the time passage of $28 \mathrm{~h}$, the water meniscus vanished. The diameter and volume changes of water meniscus are plotted in Fig.8. It can be observed that the water meniscus is shrunk in liner function of the time passage. The shape change of water meniscus should be effective to the capacitance change because of higher permittivity of water.

The time dependence of capacitance of the pn-junction array sample is shown in Fig.9a. The capacitance value was constant until 1680min in three measurement frequencies. The time at $1680 \mathrm{~min}$ corresponds to the endpoint of the meniscus drying.

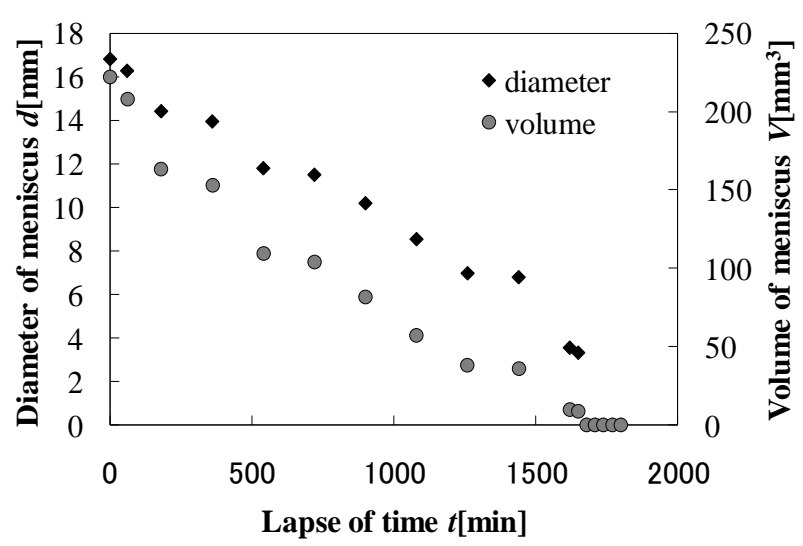

Fig.8 Time dependence of the meniscus diameter and volume 


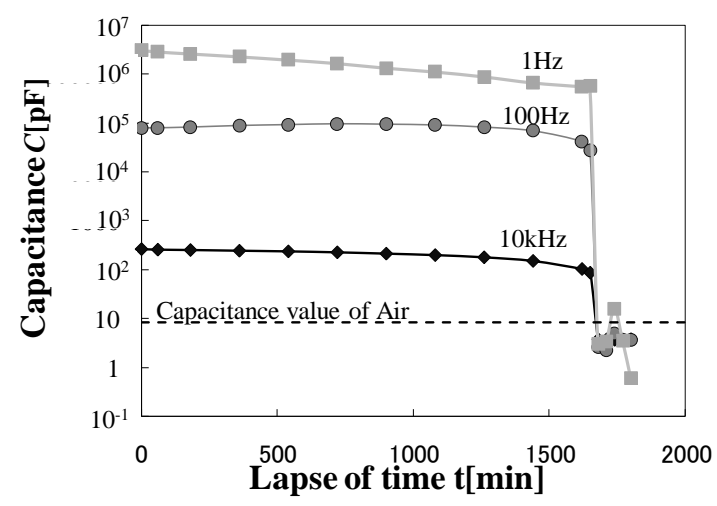

(a) Capacitance value

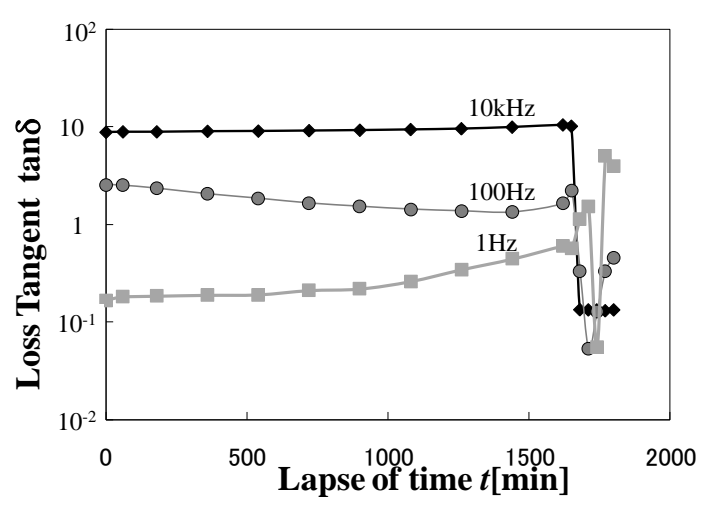

(b) loss tangent

Fig.9 Drying time dependence of capacitance and loss tangent of the water drying samples.

It is clearly observed that the capacitance decreased rapidly accompanying with water meniscus vanishing. The loss tangent variation in Fig.9b indicates the same tendency as the capacitance. It can be confirmed that the endpoint of water drying can be monitored by the electrical measurement method in this study. Particularly, in the case of pn-junction array substrate, the capacitance changes largely at a threshold of drying time. The results obtained in this study should contribute to high quality wet process control.

\section{Conclusion}

The drying behavior of water thin layer is analyzed on a gap structure with a pn-junction array and a Pt electrode. The capacitance and loss tangent are higher sensitivity to the water meniscus vanishing. The drying nature of liquid layer can be analyzed by the dielectric method. These results should contribute to a high quality control of wet processes.

\section{References}

1. A. Escarpe, M. C. González, A. G. Crevillén, and A. J. Blasco, Electrophoresis, 28 (2007) 1002.

2. J. C. Tomos, D. Lieber, J. C. Baret, A. E. Harrek, L. Frentz,J. Blouwolff, K. J. Humphry, Sarah Köster, H. Duan, C. Holtze, D. A. Weltz, A. D. Griffiths, and C. A. Merten, Chemistry \& Biology, 15 (2008) 427.

3. C. C. Chang and R. J. Yang, Microfluid Nanofluid, 3 (2007) 501.

4. E. Arai, D. Iida, H. Asai, Y. Ieki, H. Uchida, and M. Ichimura, Jpn. J. Appl. Phys., 42 (2003) 150. 